\title{
ADAPTACIÓN DE LA METODOLOGÍA DE CÁLCULO DE HUELLA ECOLÓGICA PARA LOS CULTIVOS DE PALMA AFRICANA USANDO SISTEMAS DE INFORMACIÓN GEOGRÁFICA: ESTUDIO DE CASO PUERTO WILCHES SANTANDER Analysis of the ecological footprint of African palm plantations using GIS
}

Titulo corto: Huella ecológica para cultivos de palma africana aplicando SIG

Palabras clave: huella ecológica, monocultivo, palma africana, tecnología satelital, sostenibilidad.

Keywords: ecological footprint, African palm, satellite technology, sustainability, monocropping
Claudia Ramírez, Cano ${ }^{1}$

\section{RESUMEN}

En el municipio de Puerto Wilches el monocultivo de palma africana actualmente es un eje trasversal de la economía, modificando la diversidad de los ecosistemas y cultivos tradicionales de la zona. Por lo cual, el objetivo de esta investigación es medir y evaluar los impactos de los cultivos de palma africana en el lapso de 1987 a 2010 adaptando la metodología desarrollada por Mathis Wackernagel y William Rees y algunos aportes de los desarrollos realizados por Juan Luis Doménech, aunando a estos tecnología satelital e indicadores de biocapacidad y déficit ecológico para conocer los requerimientos de espacios y recursos naturales necesarios para la producción de los derivados de la palma. El análisis de la época arrojó para el año 1987 un indicador de huella ecológica con un valor de $1.255 \mathrm{ha} / \mathrm{pc}$, biocapacidad del cultivo $0.470 \mathrm{ha} / \mathrm{pc}$, déficit ecológico correspondiente a $-0.785 \mathrm{ha} / \mathrm{pc}$; se estima un valor del $16 \%$ en cuanto a la producción y uso de recursos. Con relación a los indicadores de sostenibilidad, en 2010 se obtuvieron valores de huella ecológica de $5.492 \mathrm{ha} / \mathrm{pc}$, biocapacidad $1.454 \mathrm{ha} / \mathrm{pc}$ y déficit ecológico de $-4.038 \mathrm{ha} / \mathrm{pc}$, cifras que evidencian los efectos originados por la implementación del monocultivo en la zona, que para la fecha aumentó en un $63 \%$ la producción y uso de recursos naturales. Por lo anterior, es necesario y urgente elaborar e imple- mentar políticas de planificación territorial así como alternativas de producción económica para mejorar la calidad ambiental y social del municipio, deteniendo la acelerada antropización de la región.

\section{ABSTRACT}

African palm monoculture has modified ecosystem diversity and traditional agriculture in the municipality of Puerto Wilches. In this study we evaluate the impacts of African palm plantations in the years 1987 and 2010. We adapted the methodology of Mathis Wackernagel and William Rees with some contributions made by Juan Luis Doménech that includes satellite technology, biocapacity indicators and ecological deficit to determine the spatial and natural resource requirements for the production of palm derivatives. In 1987, an ecological footprint of $1.255 \mathrm{ha} /$ pc, crop biocapacity of $0.470 \mathrm{ha} / \mathrm{pc}$ and an ecological deficit of $-0.785 \mathrm{ha} / \mathrm{pc}$ were recorded, which indicates a value of $16 \%$ corresponding to the production and use of resources. In 2010, an ecological footprint of $5.492 \mathrm{ha} / \mathrm{pc}$, crop biocapacity of $1.454 \mathrm{ha} / \mathrm{pc}$ and an ecological deficit of $-4.038 \mathrm{ha} / \mathrm{pc}$ were measured. These rates demonstrate the effects of monocropping in the area which increased the production and use of natural resources by $63 \%$. The development and implementation of spatial planning policies as well

1 Ingeniera Ambiental Msc. cramirezcano@gmail.com 
as alternative modes of economic production are necessary to improve the environmental and social quality of the municipality, preventing the accelerated anthropization of the region.

\section{INTRODUCCIÓN}

El desafío que enfrenta la actual sociedad es encontrar una opción de sustitución energética sostenible ante la disminución en la producción generada a partir de hidrocarburos, la cual se ve amenazada por la disponibilidad requerida a largo plazo.

Por lo anterior, se han desarrollado alternativas que suponen la mitigación de impactos medioambientales a partir del aprovechamiento de la biomasa para la generación de energía, denominada biocombustible, la cual es hoy en día uno de los principales objetivos en cuanto a adelantos investigativos por los supuestos beneficios que ofrece tanto ambientales como económicos.

En Colombia, la palma africana se ha convertido en uno de las alternativas generadoras de biocarburantes, monocultivo del cual se ha abierto un gran debate en torno a los aportes sociales, económicos y ecológicos que de ellos se genera. Diferentes autores, además de los anteriormente mencionados, han concluido que este cultivo requiere condiciones físico-bióticas exigentes, ya que modifica la dinámica ecosistémica y consume recursos naturales importantes como los hídricos, edáficos, atmosféricos, etc. Proponen que se debe investigar y cuantificar más a fondo, a fin de establecer la viabilidad de la implementación y uso.

Dado lo anterior, se requiere generar indicadores que permitan mejorar el análisis de los efectos producidos por la implementación de esta agroalternativa. Esta investigación está dirigida a determinar la sostenibilidad del cultivo de palma africana para evaluar la viabilidad ambiental y económica, con el propósito de contribuir al mejoramiento, protección y la conservación de los sistemas ecológicos y la calidad de vida de la población del municipio.

Debido a los desequilibrios medioambientales que han aumentado de manera acelerada en los últimos años en el territorio colombiano, se ha hecho ne- cesario el cálculo de la huella ecológica aplicando los instrumentos contables desarrollados por Warckemagel \& Rees (1996), un método indicador que evidencia la sustentabilidad de las acciones humanas sobre el medio biofísico. Estas aplicaciones metodológicas, desarrolladas localmente, incluyen los indicadores de sostenibilidad dados en el estudio de Márquez (2000) -titulado "Vegetación, población y huella ecológica como indicadores de sostenibilidad en Colombia"-, en las mediciones de huella ecológica como herramienta para la gestión ambiental de la ciudad de Bogotá de la Contraloría de Bogotá (2002) y en los aportes de huella ecológica alimentaria de Rodríguez (2004), además del aporte de la WWF (2012) bajo el lema de "Soy Ecolombiano", para hacer uso sostenible de los recursos naturales.

En efecto, se justifica la adaptación metodológica para el cálculo de la huella ecológica de los cultivos de palma africana en el municipio de Puerto Wilches, adoptando tecnologías de punta como la satelital, la cual contribuye mediante los datos obtenidos a la construcción de la base informática, para el reconocimiento de las condiciones espaciales del territorio en estudio y para clasificar y cuantificar las coberturas vegetales presentes en el territorio durante el periodo de estudio.

Estas áreas fueron usadas para encontrar datos de entradas y salidas del modelo. Este conjugado con la metodología de huella ecológica permite la consolidación de tres indicadores: biocapacidad, déficit ecológico y huella ecológica, los cuales establecen la sostenibilidad en cada época de estudio de los monocultivos de palma africana en el territorio de Puerto Wilches.

\section{MATERIALES Y MÉTODOS}

\section{MARCO FÍSICO DEL ÁREA DE ESTUDIO}

La investigación se realizó en el municipio de Puerto Wilches, Santander (figura 1), ubicado en el margen oriental del río Magdalena, entre las confluencias de los ríos Sogamoso y Lebrija, los cuales sirven de límite territorial al sur y al norte respectivamente. Cuenta 


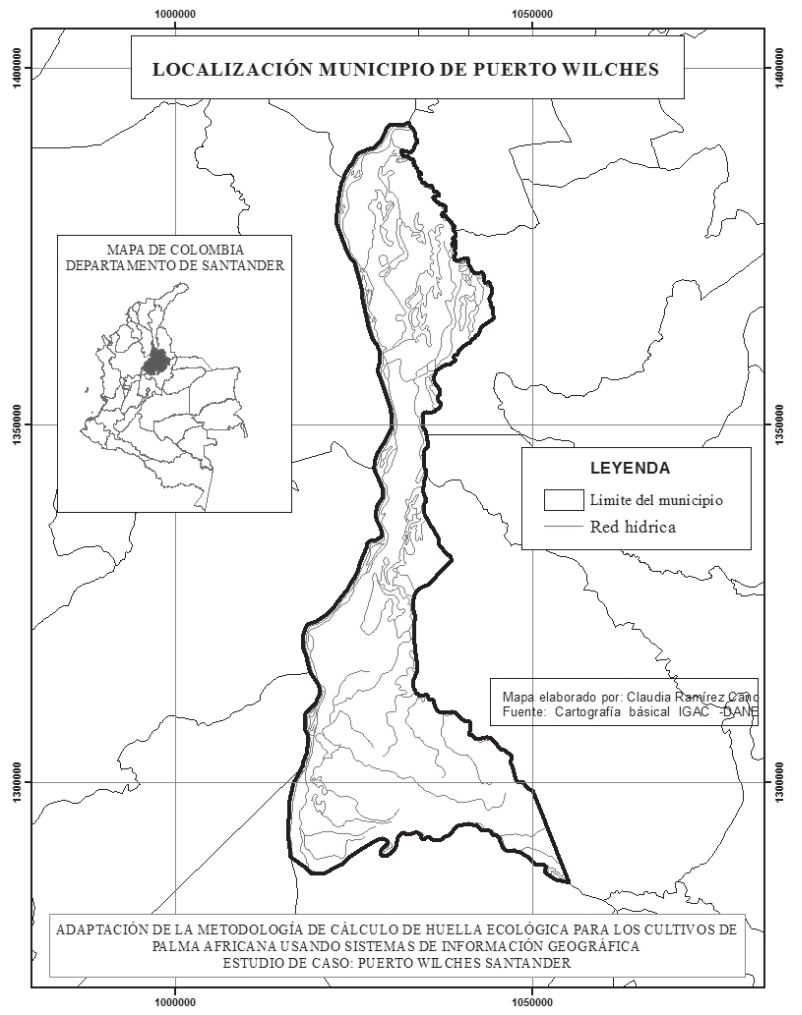

Figura 1. Mapa de ubicación geográfica del municipio con una extensión de 153916 ha y una población de 31503 habitantes, según el Esquema de Ordenamiento Territorial. Tiene una extensa zona de humedales y ciénagas y condiciones geoestratégicas (ubicación y clima principalmente) aptas para el desarrollo de este tipo de monocultivos. Por tal razón, Colombia inició el piloto de cultivos de palma con fines productivos. Este municipio en la actualidad cuenta con "cuatro plantas extractoras de aceite, además de la condición de puerto sobre el río Magdalena que facilitará las futuras exportaciones de aceite crudo de palma a través de los puertos de Barranquilla, Cartagena y Santa Marta" (Aguilera, 2002).

\section{PROCESO METODOLÓGICO DE LA INVESTIGACIÓN}

El desarrollo metodológico empleado en la presente investigación para calcular la huella ecológica de los cultivos de palma africana se desarrolló en tres fases (figura 2). La primera es el procesamiento digital de imágenes satelitales, la segunda fase corresponde al cálculo de la huella ecológica y finalmente la generación de los resultados. Estas fases son descritas a continuación.

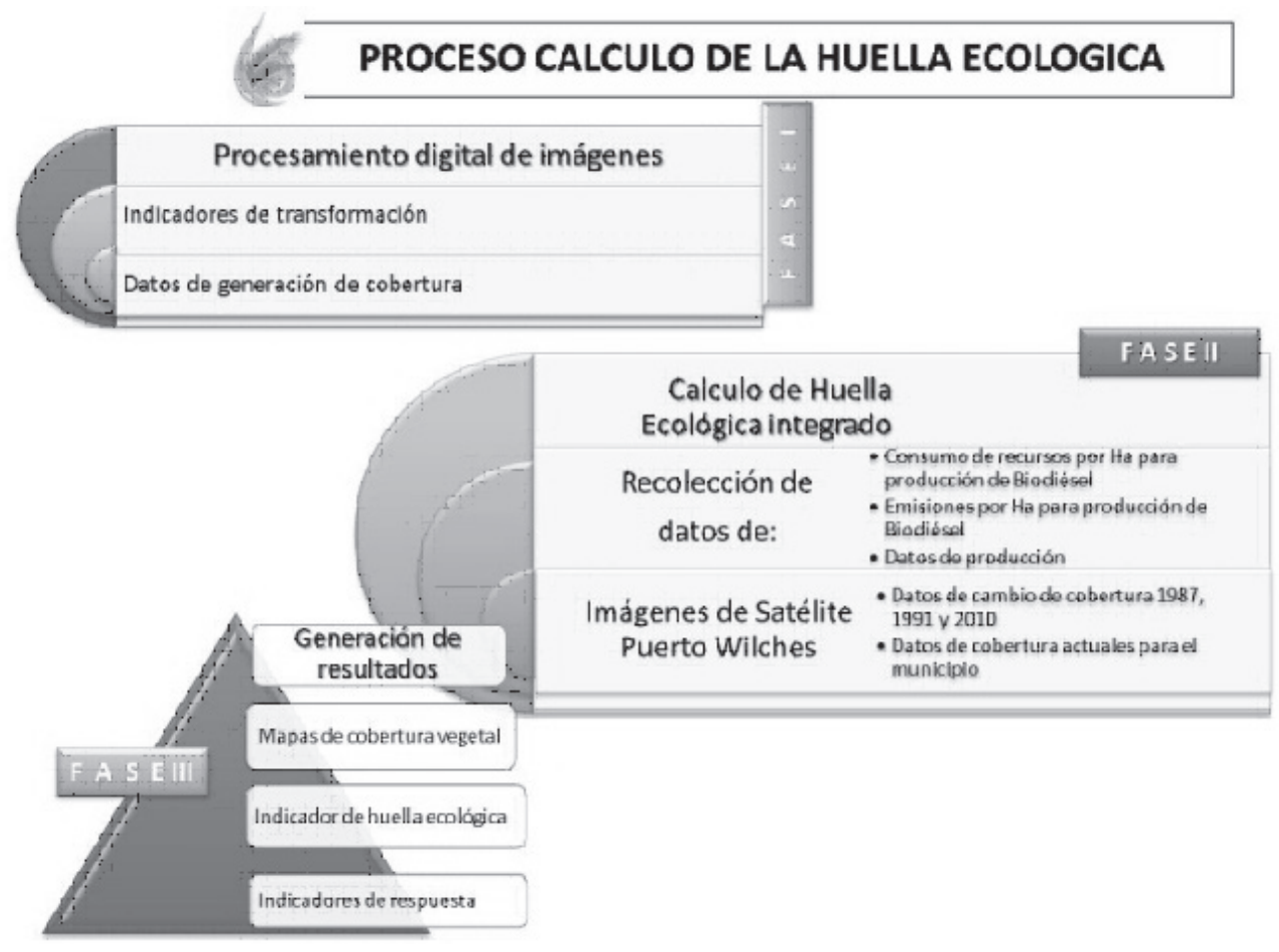

Figura 2. Metodología adaptada para el cálculo de la huella ecológica en los cultivos de palma africana 


\section{PROCESAMIENTO DIGITAL DE IMÁGENES}

Para los años de estudio: 1986, 1991 y 2010, se tomó como base la información suministrada por medio de las imágenes del satélite Landsat que proporciona sistemas de datos integrados y buena resolución.

La selección de las imágenes se realizó basada en la distribución de las escenas Landsat, la cual se hace según el sistema mundial de referencia -WRS-, y las imágenes se procesaron con los software especializados ERDAS $8.5^{\circledR}$ y ArcGis $10^{\circledR}$, que permitieron la generación de datos relacionados con la clasificación de coberturas, elaboradas a partir del sistema de clasificación de coberturas vegetales CORINE Land Cover para Colombia. Con ellos se construyeron las matrices de cambio en el software Excel $2010^{\circledR}$, con el fin de determinar las alteraciones producidas en el área de estudio.

Los datos aportados por las matrices permitieron la integralidad con la metodología desarrollada por (Doménech, 2007), en términos de transformación de territorio y desnaturalización de los ecosistemas por el remplazo mismo de las coberturas, originado por la implementación de los monocultivos de palma en el área de estudio. Además de lo anterior, se elaboró la cartografía de coberturas y uso del suelo para las décadas de los ochenta, noventa y 2000 que componen el municipio de Puerto Wilches, para dar cuenta de sus condiciones de transformación. Entre esta cartografía están los mapas de coberturas de suelos para los años 1987 y 2010 y mapas por estado de cobertura 1987-2010; estos evidencian la transformación del territorio en el periodo de estudio.

\section{CÁLCULO DE HUELLA ECOLÓGICA INTEGRADO}

Para entender el proceso productivo de los cultivos de palma se evaluaron las tres fases (previvero, vivero y plantación), las cuales contienen información que se aporta al modelo por su importancia en términos de consumo de recursos, de los productos y residuos resultado de dicho proceso.
Posteriormente, se construyeron una serie de matrices basadas en los datos de consumo obtenidos en diferentes publicaciones (Federación Nacional de Cultivadores de Palma de Aceite, s.f.) e industrias dedicadas a esta labor en el mundo, orientados en información relacionada con la generación y uso de recursos por hectárea sembrada de palma africana, además de la clasificación visual realizada a las imágenes satelitales de cada periodo en el software ArcGis $10^{\circledR}$.

Después en Excel se procedió a cruzar los datos obtenidos de cada clasificación realizada mediante tablas dinámicas. Esta relación permitió obtener información asociada en cuatro tipos de matrices, en las cuales se pueden evidenciar los cambios en el uso del suelo además de la verificación del grado de intervención antrópica, así como de procesos naturales dados en el área de estudio. Finalmente y para hacer un análisis más detallado se elaboró un cuadro que muestra las tendencias de cambio en el territorio.

Para dicho proceso se transformaron estos consumos en superficies biológicamente productivas, mediante índices de productividad neta, donde se halló la carga ecológica (consumo/desecho), interpretada como la tasa máxima de consumo de recursos y descarga de residuos que se puede sostener indefinidamente sin desequilibrar progresivamente la integridad funcional y la productividad de los ecosistemas principales, con independencia de dónde se encuentren (Jansson et al., 1994). Otra matriz corresponde a los cálculos de la "productividad ecológica realizados a partir de datos de consumo anuales y de los datos de productividad (has. Necesarias/ton. Consumidas)" (Doménech, 2007). La matriz reúne campos de consumo de recursos y emisiones originados del proceso de producción. Estos dan lugar a un indicador llamado contrahue1la, definido por Doménech (2004) como "todo aquello que nos permite reducir la huella ecológica por ahorro de consumos o por la creación de capital ecológico".

Con estos valores se generaron indicadores de ecoeficiencia que ayudan a apreciar la calidad de los aportes de la industria palmera en torno a los aspectos socioculturales, ambientales y económicos 
de la región de Puerto Wilches tras la implementación de este monocultivo.

Dentro del proceso para generar el indicador de huella ecológica se tuvieron en cuenta aspectos como el proceso productivo de los cultivos de palma en tres fases: previvero, vivero y plantación, las etapas de preparación, la siembra, así como requerimientos y emisiones del cultivo, hasta las grandes transformaciones realizadas. De estas se obtienen los subproductos de los cuales se genera la mayor alteración de los ecosistemas, para obtener las cifras relacionadas con los requerimientos en términos de recursos para el desarrollo del cultivo de la palma. Estos requerimientos permiten el siguiente desarrollo.

\section{TIERRA AGRÍCOLA}

Hace referencia al área necesaria para la producción de aceite de palma en el municipio de Puerto Wilches en los años de estudio. Se estima de acuerdo con en el consumo, en el rendimiento del cultivo así como en los aspectos propios de la economía (Hernández et al., 2004) (tabla 6).

A continuación se muestra la respectiva ecuación y los resultados se relacionan en la tabla 5 .

Tierra agricola $=\frac{\text { consumo }}{\text { rendimiento } / \text { ha }}=\frac{\sum \text { producción }+ \text { importaciones }- \text { exportaciones }}{\text { rendimiento } / \text { ha }}$

\section{ENERGÍA INCORPORADA}

Para determinar el efecto de dicha aplicación, se relaciona el potencial que añade la aplicación de fertilizantes, plaguicidas y herbicidas al cultivo, citados por el Institutito Interamericano de Cooperación para la Agricultura (IICA, 2006) y se formula conociendo los flujos de entradas y salidas de recursos o productos. Estas cifras, dadas en $\mathrm{t} /$ ha, son transformadas a unidades de energía (Gj), multiplicándolas por el factor de conversión especificado por Doménech (2004). Además de lo anterior, es necesario conocer cuál es la tasa de absorción de $\mathrm{CO}_{2}$ del catalogado Bh-T presente en la zona. En este caso concreto se toma un promedio de 3.95 tC-ha, reportada por Rodríguez \& Pratt
(1998), y finalmente se transforma en ha/pc como indicador de huella ecológica, utilizando el factor de conversión; es decir, una hectárea de bosque puede secuestrar anualmente las emisiones de $\mathrm{CO}_{2}$ generadas por el consumo de $71 \mathrm{Gj}$ de combustible líquido propuesto por Doménech (2004). A continuación se expone la ecuación aplicada. En la Tabla 7 se relacionan los resultados.

$$
\text { Energía incorporada }=\frac{(\text { compuesto aplicado }+h a) * 3,95}{\text { rendimiento } / \text { ha }}=
$$

\section{PRODUCCIÓN DE BIOMASA}

La producción de biomasa permite una reincorporación al ciclo productivo. En algunas oportunidades puede ser utilizada como fuente de energía por lo cual se considera como contrahuella, además del potencial de secuestro de $\mathrm{CO}_{2}$ (Hernández et al., 2004). Según Doménech (2004), la biomasa es calculada de la siguiente manera: $1 \mathrm{t}$ de biomasa equivale a: $0.45 \mathrm{t}$-Carbono $20 \mathrm{Gj}$, para tomar como resultado la cifra en ha/pc. Para este proceso se aplican las ecuaciones descritas a continuación. Las cifras obtenidas se muestran en la tabla 8.

$$
\begin{aligned}
\text { contra huella } & =\frac{(\text { toneladas biomasa } * 20)}{71} \\
\text { biomasa } & =(\text { ton producidad } * 0,45)
\end{aligned}
$$

\section{BIOCAPACIDAD Y HUELLA ECOLÓGICA}

La biocapacidad se resume como un indicador de sostenibilidad que refleja el equilibrio ambiental en una zona determinada. En otras palabras, Tobasura (2008) la define como la superficie de tierra disponible para un determinado nivel de producción y también se expresa en unidades de hectáreas globales. La diferencia entre biocapacidad y huella ecológica puede dar un excedente de recursos $(\mathrm{BC}-\mathrm{HE}>0)$ o un déficit ambiental $(\mathrm{BC}-\mathrm{HE}<0)$. Lo anterior se expone en la tabla 9, donde se relacionan los aspectos anteriormente mencionados. Para el cálculo de la biocapacidad se requiere conocer la extensión de las tierras en producción y las que aún están desocupadas, con su rendimiento por unidad de área. 


\section{GENERACIÓN DE RESULTADOS DE LA APLICACIÓN METODOLÓGICA}

Con base en la cartografía analizada se clasificaron y se cuantificaron las coberturas del suelo existentes en la zona objeto de estudio, con el fin de generar matrices que permitieran correlacionar datos de consumo de recursos y generación de residuos, emisiones y productos.

Esta cartografía también permitió la construcción de indicadores que pudieran determinar la capacidad de carga de este tipo de monocultivos y así establecer su viabilidad y efectividad con relación a las políticas de desarrollo sostenible y ordenación del territorio.

\section{RESULTADOS}

\section{MATRICES DE CAMBIO RELACIONAL}

En la tabla 1 los valores de las hectáreas corresponden al cambio relacional en cada cobertura. Para el periodo de 1987 a 2010 los cambios más representativos tienen relación con las transformaciones de las zonas pantanosas, con una pérdida de 12212 ha; en mosaicos de cultivos, pastos y espacios na- turales, con el reemplazo de 26114 ha, además del gran aumento relacionado con la palma africana que desplaza a zonas pantanosas, vegetación y cultivos. Dentro de esta matriz están implícitas todas las transformaciones concernientes a la antropización de la zona, las cuales además se evidencian en los mapas generados para cada época (figura 3).

\section{MATRICES DE CAMBIO POR TIPO DE COBERTURA}

En el segundo grupo de matrices se clasifican las coberturas en naturales artificiales, artificiales naturales y cuerpos de agua (tabla 3 ).

Se evidencia el gran impacto de los cultivos de palma en la zona. Aunque hay una preservación del $24 \%$ en la cobertura natural, la antropización se hace evidente en la modificación de uso del suelo en las categorías de artificial natural a artificial con un $17.5 \%$ y en los valores de cobertura relacionados con natural a artificial natural en un $13.6 \%$, que además están clasificados según la tabla 2 y representados en los mapas de categorización de los años 1987 y 2010 (figura 4).
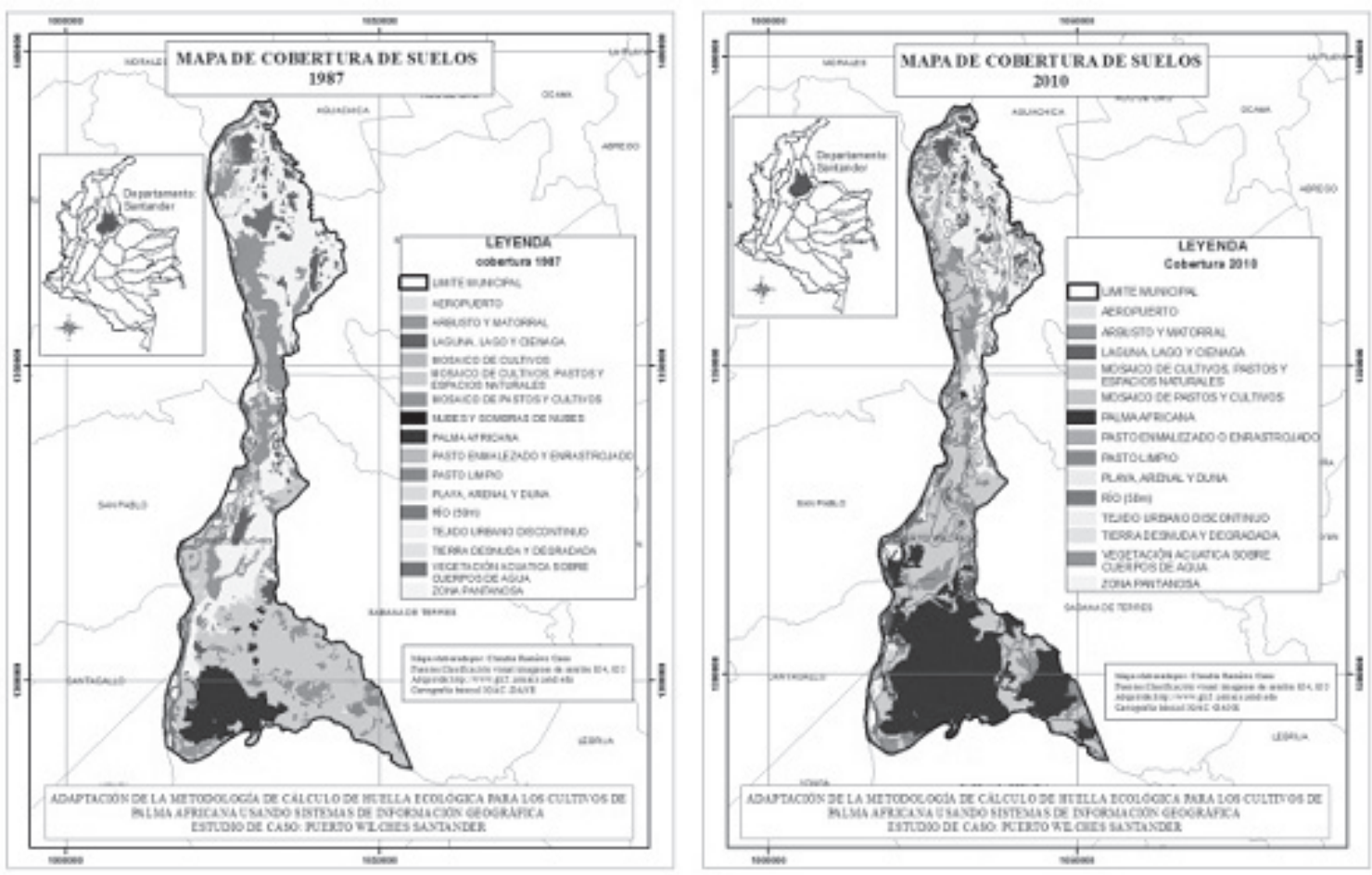

Figura 3. Mapas de coberturas de suelos para los años 1987 y 2010 
Tabla 1. Matriz de cambio relacional por tipo de uso del suelo 1987- 2010

\begin{tabular}{|c|c|c|c|c|c|c|}
\hline $\begin{array}{c}\begin{array}{c}\text { Cobertura } \\
2010\end{array} \\
\text { Cobertura } \\
1987\end{array}$ & Aeropuerto & $\begin{array}{l}\text { Arbusto y } \\
\text { matorral }\end{array}$ & $\begin{array}{c}\text { Laguna, lago } \\
\text { y ciénaga }\end{array}$ & $\begin{array}{c}\text { Mosaico } \\
\text { de cultivos, } \\
\text { pastos y } \\
\text { espacios } \\
\text { naturales }\end{array}$ & $\begin{array}{c}\text { Mosaico } \\
\text { de pastos y } \\
\text { cultivos }\end{array}$ & $\begin{array}{c}\text { Palma } \\
\text { africana }\end{array}$ \\
\hline Aeropuerto & 6.90 & & & 0.02 & & 2.09 \\
\hline $\begin{array}{l}\text { Arbusto y } \\
\text { matorral }\end{array}$ & 0.30 & 7556.51 & 54.50 & 8439.50 & 584.31 & 3681.34 \\
\hline $\begin{array}{c}\text { Laguna, lago y } \\
\text { ciénaga }\end{array}$ & & 32.76 & 4177.61 & 995.41 & 4.37 & 136.75 \\
\hline $\begin{array}{l}\text { Mosaico de } \\
\text { cultivos }\end{array}$ & & & & & & \\
\hline $\begin{array}{c}\text { Mosaico de } \\
\text { cultivos, pastos } \\
\text { y espacios } \\
\text { naturales }\end{array}$ & 3.25 & 3316.89 & 58.81 & 13211.23 & 1026.07 & 26114.01 \\
\hline $\begin{array}{c}\text { Mosaico } \\
\text { de pastos y } \\
\text { cultivos }\end{array}$ & & 116.55 & & 415.34 & 6.72 & 33.27 \\
\hline $\begin{array}{c}\text { Nubes y } \\
\text { sombras de } \\
\text { nubes }\end{array}$ & & & & 3.22 & & 273.18 \\
\hline Palma africana & 10.77 & 16.39 & & 300.80 & & 11592.79 \\
\hline $\begin{array}{c}\text { Pasto } \\
\text { enmalezado y } \\
\text { enrastrojado }\end{array}$ & & & & 102.50 & & 182.98 \\
\hline Pasto limpio & & 248.86 & & 18.58 & & 1303.28 \\
\hline Río (50m) & & 362.17 & 0.69 & 931.77 & 6.72 & 145.31 \\
\hline $\begin{array}{c}\text { Tejido urbano } \\
\text { discontinuo }\end{array}$ & 7.72 & & & 161.26 & 7.16 & 42.16 \\
\hline $\begin{array}{c}\text { Tierra desnuda } \\
\text { y degradada }\end{array}$ & 1.24 & 10.04 & & 307.42 & 0.24 & 383.69 \\
\hline $\begin{array}{c}\text { Vegetación } \\
\text { acuática sobre } \\
\text { cuerpos de } \\
\text { agua }\end{array}$ & & 32.83 & 743.84 & 545.64 & 21.37 & \\
\hline $\begin{array}{c}\text { Zona } \\
\text { pantanosa }\end{array}$ & & 4895.50 & 1711.03 & 12211.64 & 654.83 & 2154.31 \\
\hline
\end{tabular}




\begin{tabular}{|c|c|c|c|c|c|c|}
\hline \multirow{3}{*}{$\begin{array}{c}\begin{array}{c}\text { Cobertura } \\
2010\end{array} \\
\text { Cobertura } \\
1987\end{array}$} & \multirow{3}{*}{$\begin{array}{c}\text { Pasto } \\
\text { enmalezado o } \\
\text { enrastrojado }\end{array}$} & \multirow{3}{*}{ Pasto limpio } & \multirow{3}{*}{ Río (50 m) } & \multirow{3}{*}{$\begin{array}{l}\text { Tejido urbano } \\
\text { discontinuo }\end{array}$} & \multirow{3}{*}{$\begin{array}{l}\text { Vegetación } \\
\text { acuática sobre } \\
\text { cuerpos de } \\
\text { agua }\end{array}$} & \multirow{3}{*}{$\begin{array}{c}\text { Zona } \\
\text { pantanosa }\end{array}$} \\
\hline & & & & & & \\
\hline & & & & & & \\
\hline Aeropuerto & & & & 2.51 & & \\
\hline $\begin{array}{l}\text { Arbusto y } \\
\text { matorral }\end{array}$ & 143.37 & 42.47 & 290.46 & & & 3723.02 \\
\hline $\begin{array}{c}\text { Laguna, lago y } \\
\text { ciénaga }\end{array}$ & & & 41.80 & & 59.56 & 3571.15 \\
\hline $\begin{array}{l}\text { Mosaico de } \\
\text { cultivos }\end{array}$ & & & 65.54 & & & \\
\hline $\begin{array}{c}\text { Mosaico de } \\
\text { cultivos, pastos } \\
\text { y espacios } \\
\text { naturales }\end{array}$ & 10.07 & 131.89 & 1183.96 & 35.45 & & 1589.13 \\
\hline $\begin{array}{c}\text { Mosaico } \\
\text { de pastos y } \\
\text { cultivos }\end{array}$ & & & 148.14 & & & 410.03 \\
\hline $\begin{array}{c}\text { Nubes y } \\
\text { sombras de } \\
\text { nubes }\end{array}$ & & & & & & \\
\hline Palma africana & & 12.57 & 0.16 & 0.29 & & 5.42 \\
\hline $\begin{array}{c}\text { Pasto } \\
\text { enmalezado y } \\
\text { enrastrojado }\end{array}$ & & 33.91 & 4.13 & & & 23.24 \\
\hline Pasto limpio & & & & & & 0.27 \\
\hline Río (50m) & 78.29 & 2.08 & 3485.37 & 7.38 & & 3674.36 \\
\hline $\begin{array}{c}\text { Tejido urbano } \\
\text { discontinuo }\end{array}$ & & & 6.14 & 107.18 & & \\
\hline $\begin{array}{c}\text { Tierra desnuda } \\
\text { y degradada }\end{array}$ & & & 21.98 & & & 5.95 \\
\hline $\begin{array}{l}\text { Vegetación } \\
\text { acuática sobre } \\
\text { cuerpos de } \\
\text { agua }\end{array}$ & & & & & 10.16 & 1792.31 \\
\hline $\begin{array}{c}\text { Zona } \\
\text { pantanosa }\end{array}$ & 397.57 & 109.24 & 1377.19 & 53.06 & 86.26 & 24239.42 \\
\hline
\end{tabular}


Tabla 2. Clasificación de cobertura vegetal

Clasificación

\begin{tabular}{|c|c|}
\hline & Aeropuerto \\
\hline & Mosaico de cultivos \\
\hline & Mosaico de pastos y cultivos \\
\hline Artificial & Palma africana \\
\hline & Pasto limpio \\
\hline & Tejido urbano discontinuo \\
\hline & Arbusto y matorral \\
\hline & Nubes y sombras de nubes \\
\hline & Pasto enmalezado o enrastrojado \\
\hline Natural & Playa, arenal y duna \\
\hline & Vegetación acuática sobre cuerpos de agua \\
\hline & Zona pantanosa \\
\hline Artificial natural & Mosaico de cultivos, pastos y espacios naturales \\
\hline Cuerpo de & Laguna, lago y ciénaga \\
\hline agua & Río (50 m) \\
\hline
\end{tabular}

Tabla 3. Matriz de cambio por tipo de cobertura 1987- 2010

\begin{tabular}{lccccc}
\hline $\begin{array}{l}\text { Porcentaje cambios 1987 } \\
\text { - 2010 }\end{array}$ & Artificial & $\begin{array}{c}\text { Artificial y } \\
\text { natural }\end{array}$ & $\begin{array}{c}\text { Cuerpo de } \\
\text { agua }\end{array}$ & Natural & Total general \\
\hline Artificial & 8.6 & 0.8 & 0.2 & 0.5 & 10.1 \\
Artificial y natural & 17.5 & 8.4 & 0.8 & 3.1 & 29.9 \\
Cuerpo de agua & 0.2 & 1.2 & 4.9 & 5.0 & 11.3 \\
Natural & 5.0 & 13.6 & 2.7 & 27.4 & 48.7 \\
Total general & 31.3 & 24.1 & 8.6 & 36.1 & 100.0 \\
\hline
\end{tabular}




\section{MATRICES DE CATEGORIZACIÓN DE COBERTURA}

Como se relaciona en la tabla 4 y de acuerdo con la dinámica productiva de la zona, en tan solo 13 años el incremento en la pérdida de cobertura natural es del $37.4 \%$, debido a procesos de industrialización que resultan riesgosos para los ecosistemas naturales presentes en la zona. En áreas naturales tan solo hay una representación del $5.3 \%$ y con relación con 1987 se ha conservado un $57.1 \%$.
Esto se representa también en los mapas de estado de coberturas (figura 4).

Tabla 4. Matriz de transformación de cobertura 1987- 2010

\begin{tabular}{lcc}
\hline $\begin{array}{l}\text { Estado } \\
\text { 1987/2010 }\end{array}$ & $\begin{array}{c}\text { Área total } \\
\text { en ha }\end{array}$ & $\begin{array}{c}\text { Porcentaje de } \\
\text { representación }\end{array}$ \\
\hline Ganancia & 8421 & 5 \\
Perdida & 58637 & 5 \\
\hline Sin cambio & 89322 & 37 \\
\hline
\end{tabular}
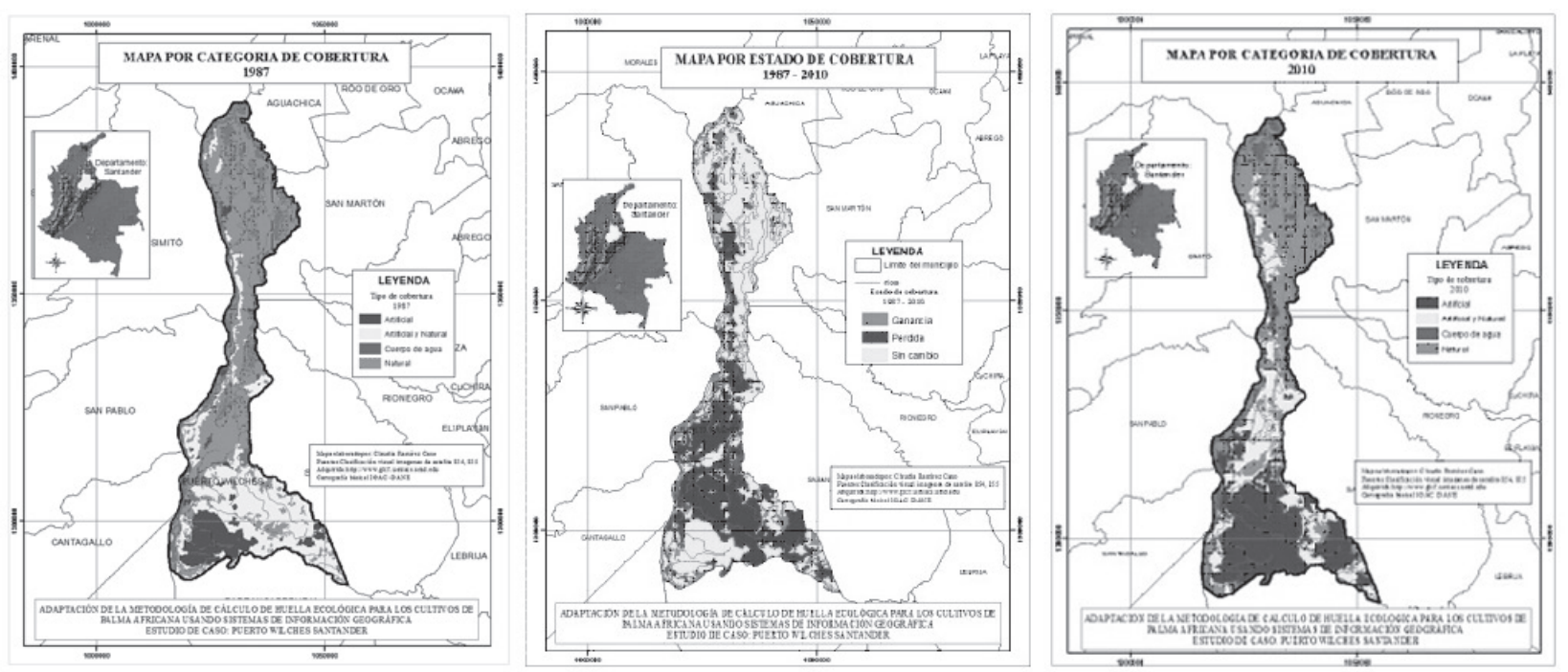

Figura 4. Mapa por estado de cobertura 1987-2010

\section{MATRICES DE TENDENCIASDE CAMBIO}

En la tabla 5 los valores mayores a $1(>1.0)$ significan un incremento o ganancia en la superficie, los valores inferiores a $1(<1.0)$ representan una reducción o pérdida de superficie y los valores iguales a 1 (=1.0) significan que no hubo cambios.

Tabla 5. Tendencia de cambio década 1987-2010

\begin{tabular}{lccc} 
Cobertura & Hectáreas año 1987 & Hectáreas año 2010 & Tendencia de cambio 1987-2010 \\
\hline Aeropuerto & 11.5 & 30.18 & 2.6 \\
Arbusto y matorral & 24293.2 & 16585.14 & 0.7 \\
Laguna, lago y ciénaga & 8952.1 & 6059.14 & 0.7 \\
Mosaico de cultivos & 65.5 & & 0.0 \\
$\begin{array}{l}\text { Mosaico de cultivos, pastos y } \\
\text { espacios naturales }\end{array}$ & 47222.2 & 37615.80 & 2.1 \\
Mosaico de pastos y cultivos & 1106.8 & 2311.97 & 3.8 \\
Palma africana & 276.4 & 45792.06 & \\
\hline
\end{tabular}




\begin{tabular}{lccc}
\hline $\begin{array}{l}\text { Pasto enmalezado y } \\
\text { enrastrojado }\end{array}$ & 11939.2 & 629.41 & 1.8 \\
$\begin{array}{l}\text { Pasto limpio } \\
\text { Playa, arenal y duna }\end{array}$ & 346.8 & 332.15 & 0.2 \\
$\begin{array}{l}\text { Río (50 m) } \\
\text { Tejido urbano discontinuo }\end{array}$ & 1571.0 & 6562.63 & 0.8 \\
$\begin{array}{l}\text { Tierra desnuda y degradada } \\
\text { Vegetación acuática sobre } \\
\text { cuerpo de agua }\end{array}$ & 8519.1 & 205.78 & 0.6 \\
\begin{tabular}{l} 
Zona pantanosa \\
\hline
\end{tabular} & 731.8 & & 0.0 \\
\hline
\end{tabular}

\section{DESARROLLO DEL CÁLCULO DE LA HUELLA ECOLÓGICA}

Huellas calculadas

Tabla 6. Subhuella tierra agrícola

\begin{tabular}{lccl}
\hline & Año 1987 & Año 2010 & Fuente \\
\hline Producción ton/ha & 47756 & 183168 & Elaboración propia \\
Rendimiento & 3 & 3.5 & Min Agricultura \\
Exportaciones ton & & 11130 & Min Agricultura \\
Consumo interno ton & 47756.4 & 171047 & Elaboración propia \\
Población municipio & 25383 & 31498 & DANE \\
Tierra agrícola ha & 15918.8 & 48870.6 & Elaboración propia \\
Tierra agrícola ha/pc & 0.63 & 1.55 & Elaboración propia \\
\hline
\end{tabular}

Se evidencia un aumento en la implementación de el uso corresponde a $0.63 \mathrm{ha} / \mathrm{pc}$. En el 2010 el valor cultivos de palma a lo largo del territorio para 1987, es de $1.55 \mathrm{ha} / \mathrm{pc}$, con un aumento de $0.92 \mathrm{ha} / \mathrm{pc}$.

Tabla 7. Subhuella energía incorporada

\begin{tabular}{lcccc}
\hline Fertilizantes & kg/ha/año & $\begin{array}{c}\text { I.E. } \\
(\mathbf{G j} / \mathbf{t})\end{array}$ & $\begin{array}{c}\text { Productiv. } \\
\text { energética }[\mathbf{G j} / \\
\text { ha/año] } \mathbf{1 9 8 7}\end{array}$ & $\begin{array}{c}\text { Productiv. } \\
\text { energética } \\
{[\mathbf{G j} / \mathbf{h a / a n ̃ o ] ~ 2 0 1 0}}\end{array}$ \\
\hline Nitrógeno & 160 & 38.90 & 0.029 & 0.090 \\
Fósforo & 70 & 10.70 & 0.015 & 0.046 \\
Potasio & 180 & 4.30 & 0.044 & 0.136 \\
Subtotal fertilizantes & & & 0.088 & 0.272
\end{tabular}

Plaguicidas-herbicidas 
Insecticidas, fungicidas, desinfectantes

Subtotal plaguicidaherbicidas

Total fertilizantes /

Plaguicida...

Energía incorporada $\mathbf{G j} / \mathbf{h a}$

Energía Incorporada ha/pc
50.00

0.132

0.220

0.352

0.704

1.290

1987 la energía incorporada tiene un valor de 1290 ha/pc y en el 2010 la cifra se relaciona con 3.989 ha/pc. El aumento es de 2699 ha/pc.
La energía incorporada aumenta de manera proporcional al incremento relacionado con la implementación del cultivo en el municipio. En

Tabla 8. Contrahuella de la producción de biomasa

\begin{tabular}{lll}
\hline & $\mathbf{1 9 8 7}$ & $\mathbf{2 0 1 0}$ \\
\hline Biomasa ton & 298477.5 & 1144800 \\
tC/ha/año & 59696 & 228960 \\
\hline ha/pc & 0.662 & 0.048 \\
\hline
\end{tabular}

Los desechos vegetales resultado de la transformación de la palma africana producen anualmente un valor aproximado de $25 \mathrm{t} / \mathrm{ha}$.

Los cálculos realizados arrojan 0.662 ha/pc para 1987 y 0.048 en el 2010, con una disminución calculada en aproximadamente $0.614 \mathrm{ha} / \mathrm{pc}$, por pudrición de cogollo, grave enfermedad originada por causas bióticas (hongos) y abióticas, por factores climáticos.

Tabla 9. Huella ecológica, biocapacidad y déficit ecológico del cultivo de palma africana en Puerto Wilches

\begin{tabular}{lll}
\hline Huella ecológica & $\mathbf{1 9 8 7}$ & $\mathbf{2 0 1 0}$ \\
\hline Tierra agrícola ha/pc & 0.627 & 1.552 \\
Tierra para energía ha/pc & 1.290 & 3.989 \\
Subtotal huellas & 1.918 & 5.540 \\
Contrahuella & 0.662 & 0.048 \\
Huella ecológica & 1.255 & 5.492 \\
Biocapacidad & 0.470 & 1.454 \\
Déficit ecológico & -0.785 & -4.038 \\
\hline
\end{tabular}


En 1987 el número de hectáreas sembradas era de 11939 , con uso de recursos y una producción del $16 \%$, obteniendo un indicador de huella ecológica de $-1.255 \mathrm{ha} / \mathrm{pc}$, biocapacidad de $0.470 \mathrm{ha} / \mathrm{pc}$ y un déficit ecológico de $-0.785 \mathrm{ha} / \mathrm{pc}$.

Para 2010, la ocupación del territorio por palma, así como la producción y generación de residuos alcanzan una cifra aproximada de $63 \%$, por cuanto el indicador de huella ecológica también aumentó a $5.492 \mathrm{ha} / \mathrm{pc}$, la biocapacidad a $1.454 \mathrm{ha} / \mathrm{pc}$, con un déficit ecológico correspondiente a $-4.038 \mathrm{ha} / \mathrm{pc}$.

\section{DISCUSIÓN}

Aunque se reconoce que el cultivo de palma africana ha sido introducido para mejorar las condiciones económicas, no solo de la región, sino también del país, esto contrasta con "las posibilidades de producción de biocombustibles en Colombia hacia la exportación limitadas, no solo por la velocidad de crecimiento o implantación de nuevos cultivos energéticos, sino también por restricciones que podrían ser impuestas en ciertos mercados" (Cardona, 2009). Razones que incrementan los impactos negativos sobre el ambiente, entre ellos la degradación del recurso suelo, hídrico y atmosférico por el abuso de sustancias que mejoran la productividad, además de controlar maleza y otro tipo de eventualidades que logran afectarlo. Así se menciona uno de los ejemplos de la situación ambiental del municipio de Puerto Wilches, relacionada con el deterioro de la quebrada "La Gómez, que ha disminuido, entre 1980 y 2005, 289 kilómetros de su red hídrica" (FIAN, 2009). Aunque Fedepalma en sus publicaciones muestra matrices de impactos y sus posibles soluciones, es indudable el poco control y la incipiente intervención de la industria en subsanar y mejorar el equilibrio ecosistémico de la región, por lo cual no solo se está afectando la calidad de ambiente en el municipio, sino que a su vez se altera la dinámica de los alrededores.

Cabe suponer que el desarrollo económico está interconectado con procesos socioeconómicos, culturales y políticos a escala global que originan cambios en las políticas locales, departamentales y nacionales, lo cual origina alteraciones en la estructura natural y social impulsadas, lógicamente, por tendencias globales. Se requiere entonces una revisión de los planes estratégicos de las entidades territoriales, los cuales deben tener una interconexión lógica entre los componentes social, ambiental y económico. Lo cual es importante para aplicar "frenos o límites al desarrollo urbano" (Fernández, 2000), desarrollo orientado al consumo y no a la producción.

Para el año base del estudio, la implementación de los monocultivos de palma en la región no generaba datos de déficit ecológico, pero se iniciaban grandes procesos de desplazamiento causados por el cambio en la orientación económica del municipio, además de los grandes yacimientos mineros en la región. Esto originó problemas de violencia. Sin embargo, pese a estos desarrollos, la población aún se veía beneficiada por algunos cultivos como yuca, plátano, cacao y explotación de otros recursos energéticos (Internacional Food First Information - FIAN, 2009), los cuales permitían a la población mejores condiciones de vida, traduciéndose en menor presión sobre los recursos naturales.

Entre tanto, las condiciones ambientales del municipio comenzaban a verse afectadas por el cambio en el uso del suelo, así como por la pérdida y extinción de especies y ecosistemas regionales. La implementación del monocultivo de palma, además del aspecto ambiental que empieza a afectar al sector, no cabe duda de que hacen que la vulnerabilidad de los pobladores empiece cobrar relevancia debido a la homogeneidad de las posibilidades económicas.

Para 2010, el incremento en el valor de huella ecológica se da por los procesos industriales a gran escala originados por la siembra de palma africana en la zona, cosechada para beneficio de sus subproductos y la generación de alternativas energéticas como el biodiesel. Con relación a este aumento se da la ampliación de áreas destinadas para aeropuertos, lo que beneficia particularmente a los terratenientes de la zona. Los demás incrementos pueden relacionarse con zonas que posiblemente estuvieran destinadas para cultivos de palma. 
Las cifras en aumento están muy relacionadas con la afectación del equilibrio medioambiental y el aumento en los problemas sociales debido a la pérdida del valor de los recursos. El desarrollo de este tipo de actividades económicas de gran escala posiblemente carezca de estudios y evaluaciones de impacto claras, concretas y reales. La escasa planificación conlleva siempre obtener resultados inviables, por los costos ambientales y sociales que se producen. Esto se ve reflejado en el indicador de necesidades básicas insatisfechas, que según el Departamento Administrativo Nacional de Estadística -DANE- (1993), en este caso fue de $64.02 \%$. Resultado que refleja la problemática económica de la zona y la gran afectación de las condiciones vida de la población.

Evidentemente y como ya se ha mencionado, las estadísticas del Plan de Desarrollo comprueban el grave problema que enfrenta la comunidad de Puerto Wilches al encontrar una restricción en las posibilidades económicas que conduzcan al mejoramiento de la calidad de vida. En el boletín Censo General DANE (2005), la pobreza muestra una proporción del $48 \%$ y un índice de calidad de vida del $65 \%$ para el mismo año de estudio. Con relación a las condiciones ambientales del municipio, es claro que los efectos originados por este desarrollo industrial se relacionan con el anuncio de Amigos de la Tierra (2008), de acuerdo con el cual:

"Deforestación masiva, destrucción de ecosistemas, especies en peligro de extinción, impacto social sobre las poblaciones locales, violación de los derechos humanos, impactos sobre la soberanía alimentaria [...] El cultivo industrial de la palma supone hoy en día una grave amenaza ambiental y el principal motor que está disparando su ya de por si elevada demanda son los agrocombustibles".

Por consiguiente, cabe resaltar el anuncio de la EPA (citada por Fedebiocombustibles, 2007):

\footnotetext{
"ha declarado que el biodiesel de aceite de palma no llena los requisitos exigidos por la normatividad americana, que señala como combustibles alternativos los que reduzcan un mínimo de $20 \%$ de las emisiones de los combustibles fósiles".
}

Además de lo anterior, hay estudios que demuestran la grave situación que experimentan algunos cultivos de palma en la región de Puerto Wilches por pudrición de cogollo (PC). En Vanguardia (2011) se publicó que en el municipio se erradicarían 12498 ha, lo cual conlleva implicaciones sociales, ambientales y económicas, porque este tipo de eventualidades requieren alternativas de amortiguación financiera que posiblemente el Gobierno nacional no esté en condiciones de suministrar.

Finalmente y pese a las investigaciones desarrolladas en el mundo para conocer el potencial y el verdadero aporte de este monocultivo, este aún es incierto, pero sin duda los efectos ocasionados en las comunidades y el medio ambiente dejan hasta ahora una gran marca que altera el equilibrio y buen desarrollo de los ecosistemas y la sociedad en esta región tan permeada por problemas políticos y económicos.

La generación de indicadores de sostenibilidad y la tecnología satelital constituyen herramientas que contribuyen de manera importante a los procesos de gestión territorial. Por esto que sirven de base para generar instrumentos que aporten a la preservación y conservación del medio natural, bajo el precepto de que "una comunidad se siente insegura cuando carece de seguridad ecológica, social, económica, energética, jurídica e institucional y seguridad, soberanía y autonomía alimentaria" (Arias, 2010). Padecimientos de la población ante escenarios de conflictos de toda índole que repercuten en la sostenibilidad del desarrollo económico de la región.

Por lo anterior, se resalta la necesidad de realizar análisis de la funcionalidad de las regiones, municipios o ciudades, mediante cualquier tipo de tecnología o herramienta para generar alternativas adecuadas de ordenación y planificación del territorio fundamentadas en la investigación, la voluntad política y social, que hagan frente a los problemas de cada nación y en las cuales exista una nueva concepción productiva, a partir de alternativas gestadas en la democracia, respetando los niveles de equilibrio de la naturaleza, así como la cultura y los procesos históricos de la población. Por esto que se deben utilizar herramientas como la huella ecológica y tecnología satelital para generar instrumentos y políticas de ordenación que posibiliten el desarrollo 
y buen uso de los recursos. Con ellos se deben regular las actividades para potenciar los territorios, mediante la valoración de la biodiversidad y la relación sinérgica entre la sociedad y la naturaleza.

\section{CONCLUSIONES}

Los valores de indicadores de sostenibilidad obtenidos demuestran que la actividad y el cambio de uso del suelo generado por la implementación de los cultivos de palma africana en la zona de Puerto Wilches son insostenibles, pues representan un gran impacto por el uso a gran escala de recursos naturales e, intrínsecamente, los residuos y las emisiones producidas.

Por lo anterior se ha convertido en una amenaza no solo para los ecosistemas presentes en esta zona, sino también para el potencial de sostenibilidad de la comunidad, al convertirse en un rival para las zonas destinadas a la alimentación y sustento de la población. Esto se refleja en el límite de uso que los pobladores pueden dar a su territorio.

En este contexto, las siembras de solo palma africana son causales importantes de la transformación social y ambiental del municipio. Los campesinos cambiaron abruptamente su cultura agrícola para aceptar estos nuevos cultivos, los cuales limitan el desarrollo regional y al mismo tiempo contribuyen al deterioro de los terrenos, de la fauna y de los cultivos de pancoger, precarizando la calidad de vida de la población. Esto se evidencia en las cifras tomadas de los planes de desarrollo del municipio que demuestran la grave situación de salud, desplazamiento y pobreza que se presenta por la falta de acceso a una economía variada que beneficie a los pobladores y mejore sus condiciones de vida. Por esto es importante que con estos argumentos los entes correspondientes creen alternativas dignas con el fin de lograr un progreso mancomunado.

Por estos motivos y ante la relevancia que ha adquirido el cultivo de palma se generó el cálculo de la huella ecológica para el municipio de Puerto Wilches, cálculo que permitió evaluar las condiciones del municipio con relación al cambio de uso del suelo y a su sostenibilidad. Las cifras denotan el déficit ecológico que tiene este monocultivo en el municipio. Aunque esta investigación tenga limitaciones de información y por ende se requiera un análisis más profundo, proporciona a las autoridades municipales información razonable que permite orientar políticas de ordenamiento del territorio así como alternativas agrarias que permitan una dinámica económica accesible a toda la población.

\section{AGRADECIMIENTOS}

Se reconoce el aporte de instituciones como el Ministerio de Agricultura y el DANE. Se agradece a los aportantes anónimos dentro del desarrollo de la investigación.

\section{REFERENCIAS BIBLIOGRÁFICAS}

Aguilera, M. (2002). Palma africana en la costa Caribe: un semillero de empresas solidarias. Recuperado el 27 de octubre de 2010, del Centro de Estudios Economicos regionales Banco de la Republica, http://www.banrep.gov.co/ documentos/publicaciones/pdf/DTSER30-Palma-Africana.pdf

Amigos de la Tierra (2008). Aceite de palma: usos, orígenes e impactos. Madrid, España. Recuperado de http://www.tierra.org/spip/ IMG/pdf/Aceite_de_Palma.pdf

Arias, E. (2010). Año internacional de la biodiversidad. Retos y oportunidades hacia 2020. Memorias 2010 (pp. 38-76). Bogotá: Instituto de Investigación de Recursos Biológicos Alexander von Humboldt.

Cardona, C. (2009). Perspectivas de la producción de biocombustibles en Colombia: contextos latinoamericano y mundial. Revista de Ingeniería, 29, 118.

Contraloría de Bogotá (2002). Informe anual sobre el estado de los recursos naturales y del ambiente vigencia 2002. Recuperado el 26 de agosto de 2011, de http://pqr.contraloriabogota.gov. co/intranet/contenido/FIMA/INFORMES\%20 
PUBLICADOS\%20DE\%20RECURSOS\%20 NATURALES/2003/HEINFOFN.doc.

Departamento Administrativo Nacional de Estadística-DANE- (1993). Censo general 2005: Perfil Puerto Wilches Santander. Recuperado de http://www.dane.gov.co/files/censo2005/ PERFIL_PDF_CG2005/68575T7T000.PDF

Departamento Administrativo Nacional de Estadística -DANE- (2005). Estimación y proyección de población nacional, departamental y municipal por sexo, grupos quinquenales de edad y edades simples de 0 a 26 años 1985-2020. Recuperado de http://www. dane.gov.co/index.hp?option=com_content\&view $=$ article $\& i d=75 \&$ Itemid $=72$

Doménech, J. (2004). Guía metodológica para el cálculo de la huella ecológica corporativa. Terceros Encuentros Internacionales sobre "desarrollo sostenible y población” (pp. 80-87). Málaga: Universidad de Málaga.

Doménech, J. (2007). Huella ecologica y desarrollo sostenible. Madrid: Aenor. 377 p.

ESRI (2011). ArcGis Desktop: Release 10. Redlans, CA: Enviromental Sistem Research Institute.

ERDAS (2002). ERDAS Image field guide $\left(8^{\text {th }}\right.$ ed.). ERDAS. Atlanta, GA, USA.

Federación Nacional de Biocombustibles de Colombia (2012). Confirman que biodiesel de palma colombiano es sostenible y reduce en más de $83 \%$ emisiones de gases efecto invernadero. Boletín 63. Recuperado de http://www. fedebiocombustibles.com/files/boletin63.pdf

\section{Federación Nacional de Cultivadores de Palma} de Aceite (s.f). Medio ambiente. Recuperado el 22 de octubre de 2010, de http://www.fedepalma.org/palma.htm

Fernández, R. (2000). La ciudad verde. Teoría de la gestión ambiental urbana (pp. 28-64, 42102). Buenos Aires: Espacio Editorial.
Gobierno de la Ciudad (2012). Plan de Desarrollo 2012-2015 "primero la gente" (pp. 45, 48). Recuperado de http://puertowiches-santander.gov.co/apc-aa-files/Plan_de_desarro1lo_PUERTO_WILCHES.pdf.

Hernández, E., López, F., Alonso, F., Conesa, C., \& Álvarez, R. (2004). La huella ecológica del cultivo del olivo en España y su aplicabilidad como indicador de agricultura sostenible. Revista Papeles de Geografía, 39, 141-155.

Internacional Food First Information -FIAN(2009). Resultados de la misión internacional de verificación sobre los impactos de los agrocombustibles en Colombia, Informe Regional Magdalena Medio. Recuperado de http://retornoalaspavas.files.wordpress.com/2011/02/informe-fian-palma-en-el-magadalena-medio.pdf

Instituto Interamericano para la cooperación para la Agricultura -IICA- (2006). Cultivo de la palma africana, guía técnica. Managua, Nicaragua. Recuperado de http://wwwgaleon. com/subproductospalma/guiapalma.pdf.

Jansson, A., Hammer, M., Folke, C., \& Costanza, R. (1994). Investing in natural capital: an approach to ecological sustentability. Recuperado de http://books.google.com

Márquez, G. (2000). Vegetación, población y huella ecológica como indicadores de sostenibilidad en Colombia. Gestión y Ambiente, 5, 33-49.

Ministerio de Agricultura y Desarrollo Rural (1998). Anuario Estadístico del Sector Agropecuario y Pesquero 2010 (pp. 64-66). Bogotá: Ministerio de Agricultura y Desarrollo Rural.

Ministerio de Agricultura y Desarrollo Rural (2011). Anuario Estadístico del Sector Agropecuario y Pesquero 2010. Capítulo palma (pp. 100-02, 195). Bogotá: Ministerio de Agricultura y Desarrollo Rural. 
Organización de las Naciones Unidas para la Alimentación y la Agricultura (2008). El estado mundial de la agricultura y la alimentación 2008. Recuperado de ftp://ftp.fao.org/ docrep/fao/011/i0100s/i0100s05.pdf

Rodríguez, B. (2004). Nuestro pan de cada día: Huella ecológica alimentaria de Bogotá. Recuperado el 5 de marzo de 2011, de http://observatoriogeograficoamericalatina.org.mx/egal10/Geografiasocioeconomica/Geografiaagricola/37.pdf

Rodríguez, J. \&, Pratt, L. (1998). Potencial de carbón y fijación de dióxido de carbono de la biomasa en pie por encima del suelo en los bosques de Costa Rica. Recuperado de http://www.incae.edu/es/clacds/publicaciones/pdf/cen762.pdf

Tobasura, I. (2008). Huella ecológica y biocapacidad: indicadores biofísicos para la gestión ambiental. El caso de Manizales, Colombia. ECOCRI. Recuperado de http://www.ucm.es/ info/ec/ecocri/cas/Tobasura_Acuna.pdf

Vanguardia (2011). Erradicarán $12 \mathrm{mil} \mathrm{hec-}$ táreas de palma con PC en Puerto Wilches. Recuperado de http://www.vanguardia.com/ historico/92759-erradicaran-12-mil-hectareasde-palma-con-pc-en-puerto-wilches

Warckernagel, M., \& Rees, W. (1996). Our ecological footprint. Reducing human impact on the Earth. Gabriola Island, BC, Canadá: New Society Publishers.

World Wild Life Fund -WWF- (2012). Huella ecológica. Recuperado el 10 de abril de 2011, de http://www.soyecolombiano.com/site/nuestra-huella/huella-ecologica.aspx 